\title{
Sociodemographic factors related with emergency colorectal cancer surgery at a referral center in Mexico
}

Factores sociodemográficos asociados a cirugía de cáncer colorrectal de urgencia en ựn centro de referencia en México

Omar Vergara-Fernández, Mario Trejo-Avila*, Oscar Santes, Danilo Solórzano-Vicuña, Paulina Moctezuma-Velázquez, Juan C. Sainz, Francisco Alvarez-Bautista, and Noel Salgado-Nesme Departamento de Cirugía de Colon y Recto, Instituto Nacional de Ciencias Medicas y Nutrición Salvador Zubirán, Mexico City, Mexico

\begin{abstract}
Background: Diagnosis of colorectal cancer (CRC) after emergency presentation is associated with a worse prognosis. Aim: The aim of the study was to determine the sociodemographic factors related with emergency CRC surgery at our insistitution. Methods: From January 2009 to December 2017, patients that underwent CRC surgery at our institution were inclüded in the study. Univariate and multivariate logistic regression were used to determine the effect of the potential risk factors on the rate of emergency surgery. Results: $A$ total of 247 patients underwent CRC surgery at our institution. The rate of emergency surgery was $7.7 \%$. On univariate analysis, patients without a family history of cancer (odds ratio [OR]: 4.95), living in a rural area (OR: 3.7), and late clinical cancer stage (OR: 5.06) were associated with emergent surgery. Mid-income status was a protective factor for emergency surgery (OR: $0.14, p=0.003)$. On multivariate analysis, late clinical cancer stage (OR: 4.41 , 95\% Cl 1.21-16.05, $p=0.024$ ) and mid-income economic status (OR: $0.41,95 \% \mathrm{Cl} 0.04-0.55, p=0.004$ ) were identified as independent risk factors for emergency surgery. Conclusion: Social, economic, and demographic factors were identified as predictors for emergent CRC surgery.
\end{abstract}

Key words: Colorectal cancer. Emergency colorectal surgery. Late diagnosis.

\section{Resumen}

Antecedentes: El diagnóstico de cáncer colorrectal (CCR) en el contexto de urgencia está asociado a un mal pronóstico. Objetivo: Determinar los factores sociodemográficos asociados a cirugía de urgencia en el CCR en nuestra institüción. Método: De enero de 2009 a diciembre de 2017 se incluyeron los pacientes operados de CCR y se realizaron anălisis univariado y multivariado para determinar los potenciales factores de riesgo. Resultados: Se incluyeron en el estudioż247 pacientes operados de CCR. El 7.7\% de las cirugías fueron de urgencia. En el análisis univariado, los pacientes sih antecedentes familiares de cáncer (odds ratio [OR]: 4.95), los habitantes de zonas rurales (OR: 3.7) y aquellos en etapas avanzadas del cáncer (OR: 5.06) se asociaron a cirugía de urgencia. Los pacientes con nivel socioeconómico medio tuvieron menos probabilidad de que su cirugía fuera de urgencia (OR: 0.14; $p=0.003$ ). En el análisis multivariado, debutar coñuna etapa clínica avanzada (OR: 4.41; intervalo de confianza del 95\% [IC95\%]: 1.21-16.05; $p=0.024$ ) y tener un nivel sōcioeconómico medio (OR: 0.41; IC95\%: 0.04-0.55; $p=0.004$ ) fueron factores independientes para cirugía de urgencia por $\bar{E} C R$. 
Conclusiones: Los factores sociales, económicos y demográficos se encontraron relacionados con la necesidad de cirugía de urgencia por CCR.

Palabras clave: Cáncer colorrectal. Cirugía colorrectal de urgencia. Etapa avanzada.

\section{Introduction}

Colorectal cancer (CRC) represents the third most common cancer worldwide, registering an estimated $1,096,601$ new cases, and ranks second in terms of mortality, accounting for 551,269 deaths in $2018^{1}$.

The clinical presentation and management of patients with this type of neoplasm have several implications for survival ${ }^{2}$. In spite of prevention and early detection programs, CRC requiring emergency surgical management comprises up to $26 \%$ of cases $^{3}$. The reasons for emergency surgery comprise obstruction, perforation, peritonitis, and less frequent bleeding ${ }^{4}$.

Compared with elective CRC resection, emergency surgery has been associated with a longer hospital stay ${ }^{5}$, and higher perioperative morbidity and mortality ${ }^{6}$.

Oncological long-term outcomes of emergency surgery are not well defined. Greater overall mortality has been observed in patients requiring emergency surgical management; however, it is not known if the surgical procedure itself predisposes to inferior survival ${ }^{4,7,8}$.

Owe to the worse prognosis of emergency CRC surgery, finding the social, demographic, and economic factors associated with this presentation represents an important issue to promote policies aimed to reduce the number of emergency cases; especially in developing countries where screening uptake is lower than recommended, health access barriers exist (either geographical or financial), and disparities in health-care system predominate ${ }^{9}$.

The aim of the study was to determine the sociodemographic factors related to emergency CRC surgery at our institution.

\section{Materials and methods}

From January 2009 to December 2017, all patients that underwent CRC surgery at Instituto Nacional de Ciencias Médicas y Nutrición "Salvador Zubirán" in Mexico City, Mexico, were included in the study. Data from the medical records were retrospectively retrieved and analyzed. Patients with incomplete data were excluded from the study. The study was in accordance with the ethical standards of our institutional research committee.
Socioeconomic and demographic factors included in the study were sex, age (categorized as under 50 , between 50 and 70 , and over 70 years old), patients comorbidities and previous diagnosis of another "cancer, family history of cancer (first and second degree relatives with any type of cancer), socioeconomic status (low, mid, and high) as determined by our social workers, marital status (single, married, divorced, and widowed), place of residence (urban or rural), education level (illiterate, literate, college, and above), and religion (catholic, muslim, jew, or others). The socioeconomic status was determined by the social workers of our institution and was calculated according to mean income, number of individuals depending on this income, mean expense, employment, and housing characteristics. Urban residency was considered when living in a place with more than 2500 inhabitants. Rural residency was considered when living in a place with $<2500$ inhabitants and is located outšide cities. Education level was divided in illiterate (patients unable to read or write), literate (we include in this definition to patients who read and write, and patients who had pre-college studies), and college (patients with university studies).

CRC diagnosis was confirmed with histology of the primary site (either with colonoscopy or after surgical resection). Diagnosis by screening colonoscopy ¿was registered. Staging evaluation included thoracic cómputed tomography (CT) scan, contrast-enhanced abdominopelvic CT scan, colonoscopic evaluation as required, carcinoembryonic antigen, and pelvic magnetic resonance for rectal cancer. The staging evaluation was completed after surgical resection in patients with an emergency presentation. Patients with elective rešection completed their staging before surgery. Location of the primary tumor site was analyzed. Clinical stage was determined according to the American Joint Committee on Cancer (AJCC) Cancer Staging Manual eighth edition and expressed as tumor, node, metastasis (TNM).

\section{Statistical analysis}

All data were collected retrospectively in a digital database. Patients were divided in two groups depending on their type of surgery: elective surgery and 
emergency surgery. Categorical data were presented as totals ( $\mathrm{n}$ ) and proportions as percentages. Categorical data were compared using the Chi-square test or Fisher's exact test (analyzing patients in two groups: elective vs. emergency groups). All tests were twosided and used an alpha of 0.05 .

Univariate binomial logistic regression analysis was performed. All variables with a $\mathrm{p}$-value inferior to 0.05 in the univariate analysis were considered as potential risk factors (predictors of emergency CRC surgery) and were entered manually into the multivariate forward logistic regression analysis. The variables representing the lowest risk for emergency CRC surgery were considered to be the reference group (odds ratio $[\mathrm{OR}]=1.0)$. OR and $95 \%$ confidence intervals $(95 \%$ $\mathrm{Cl})$ were calculated. Models were checked for the goodness of fit using the Hosmer-Lemeshow test. All $p$-values were 2-tailed and a $p$-value $<0.05$ was considered to be statistically significant. All data were analyzed using SPSS statistic Version 22.0 (IBM Corporation, Armonk, New York, NY).

\section{Results}

A total of 247 patients underwent CRC surgery at our institution during the years 2009 to 2017 . Of these, $228(92.3 \%)$ patients underwent elective surgery and 19 (7.7\%) underwent emergency surgery.

Patients' demographics, socioeconomic, and clinical factors are summarized in table 1. There were significant differences between the two groups regarding the family history of cancer, income status, place of residence, and tumor clinical stage (Table 1).

On univariate comparison, patients with $\mathrm{CRC}$ that had a higher risk of emergent surgery were those presenting on late clinical stage (OR 5.06; 95\% Cl 1.43-17.84), living in a rural area (OR $3.7 ; 95 \% \mathrm{Cl} 1.35$ 10.13), and patients without a familial history of any cancer (OR 4.95; 95\% Cl 1.11-21.99). On multivariate analysis, late clinical cancer stage remains as an independent risk factor for emergency CRC surgery (OR 4.41; 95\% Cl 1.21-16.05) (Table 2).

Mid-income status was a protective factor for emergency surgery (OR $0.143 ; 95 \% \mathrm{Cl} 0.04-0.50)$ in the univariate analysis as well as in multivariate analysis (OR 0.41; 95\% Cl 0.04-0.55) (Table 2).

\section{Discussion}

We found in this retrospective study a $7.7 \%$ rate of emergency CRC surgery. Although some patient-related factors, such as the family history of cancer, income status, place of residence, and TNM clinical stage, demonstrated a significant difference in the univariate analysis, only income status and clinical stage remained as independent predictors in the multivariate analysis. We must highlight the concerning low rate of CRO diagnosed by screening colonoscopy (only 5.3\%).

Patients with colon cancer treated as emergency cases have poorer post-operative outcomes and 0 oncologic results than patients who undergo elective surgery and represent a heavier economic burdenfor health systems ${ }^{5,9,10}$. In some series from Ireland ${ }^{11}$, the United Kingdom ${ }^{12}$, or Sweden ${ }^{13}$, up to $20-30 \%$ of 9 patients present to the emergency department as their first consultation for the diagnosis of colon cancer.

Mexico is considered to be a developing country, and this notion is explained by the fact that people have a lower life expectancy, less education, and less money, and women have higher fertility and pregnancy rates. In our study, we only found $7.7 \%$ of patients presented as an emergency, that is less than expected considering that our country is a developing country. For example, a group from South Africa, also a developing country, reported $14 \%$ of emergency cases ${ }^{4}$. There is a lack of data about this issue in Latin Anè can countries, and to the best of authors' knowledge, this represents the first study in Latin America.

This low percentage of patients presenting ass an emergency in our study may be due to some factors; our hospital is not a general or first contact hospital where maybe the percentage of emergency cases may be higher; on the other hand, people with collon cancer emergency may die at home or in another hospital even under-diagnosed. We cannot say that our high percentage of elective cases is a result of extensive CRC screening as only $5.3 \%$ of our elective surgical patients were diagnosed during a screening colonoscopy.

The objective of this work was to identify the characteristics among patients with colon cancer treated with emergent surgery. In our study, one of the variables identified in the univariate analysis as a isk factor for the emergency presentation was to have a low income, but in the multivariate analysis, this association was not demonstrated. Not having a Jow income was associated with elective surgery. 敌is situation reflects the problem that other health systems are facing; the socially deprived have lessaccess to screening and/or health services ${ }^{15,16}$, resulfing in a more advanced disease that frequently presents as an emergency ${ }^{17}$. 
Table 1. Patient demographics and clinical features $(n=247)$

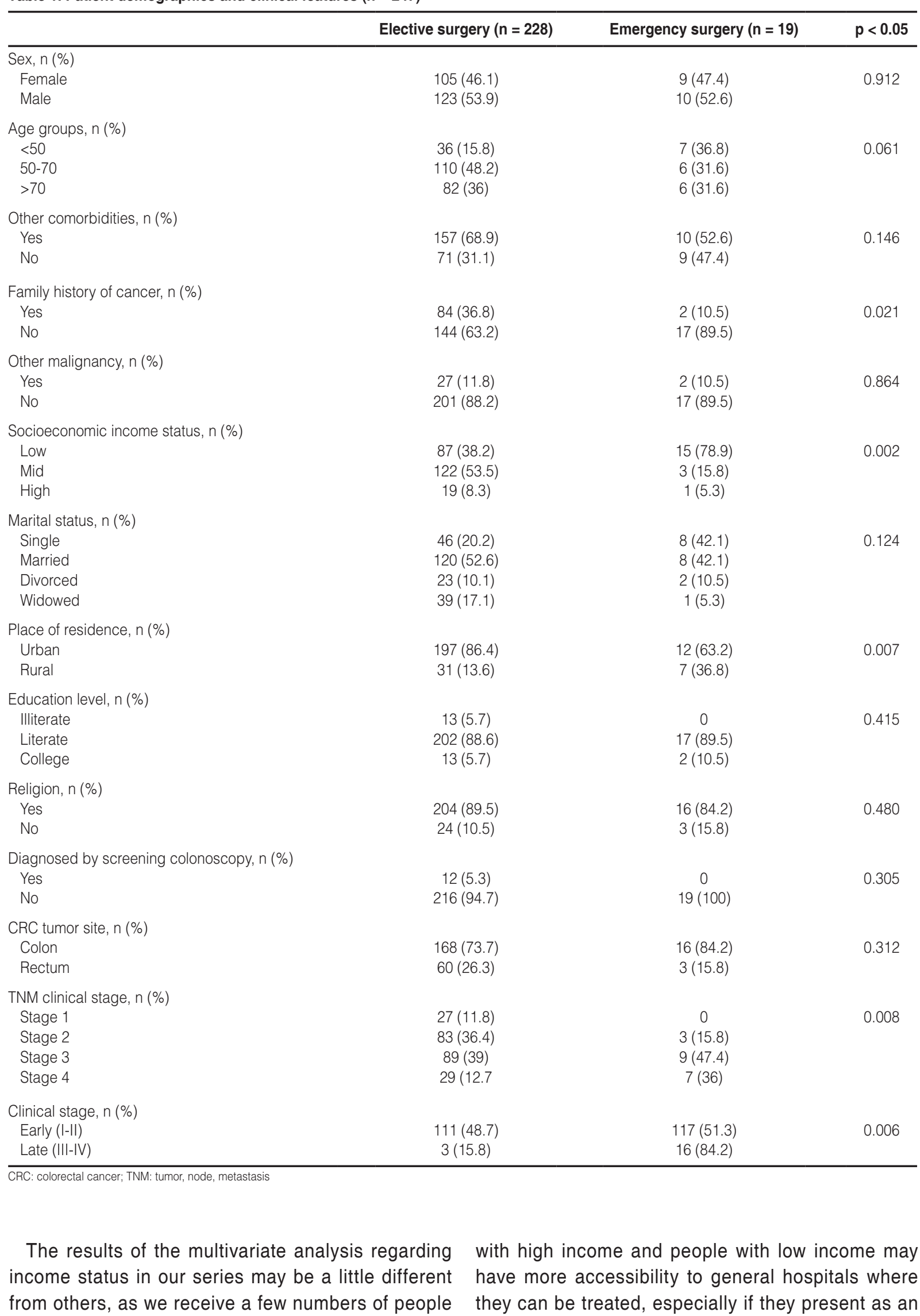


Table 2. Univariate and multivariate analysis of factors associated with emergency colorectal cancer surgery

\begin{tabular}{|c|c|c|c|c|}
\hline \multirow[t]{2}{*}{ Factors } & \multicolumn{2}{|c|}{ Univariate analysis } & \multicolumn{2}{|c|}{ Multivariate logistic regression } \\
\hline & Unadjusted OR (95\% Cl) & $p$ value & Adjusted OR (95\% Cl) & $\mathrm{p}$ vălue \\
\hline Family history of cancer, $\mathrm{n}(\%)$ & & & & $\frac{c}{c}$ \\
\hline Yes & 1 (Reference) & & & है \\
\hline No & $4.95(1.11-21.99)$ & 0.035 & & $\frac{1}{8}$ \\
\hline \multicolumn{5}{|l|}{ Income status, $\mathrm{n}(\%)$} \\
\hline Low & $3.27(0.40-26.33)$ & 0.264 & - & ᄃ் \\
\hline Mid & $0.143(0.04-0.50)$ & 0.003 & $0.41(0.04-0.55)$ & 0.004 \\
\hline High & 1 (Reference) & & &.$\underline{\underline{U}}$ \\
\hline Place of residence, $\mathrm{n}(\%)$ & & & & $\frac{2}{2}$ \\
\hline Urban & 1 (Reference) & 0.011 & & $\bar{\sigma}$ \\
\hline Rural & $3.70(1.35-10.13)$ & & & ฮิ \\
\hline \multicolumn{5}{|l|}{ Clinical stage, $\mathrm{n}(\%)$} \\
\hline Early $(I-I I)$ & 1 (Reference) & & 1 (Reference) & 0.024 \\
\hline Late (III-IV) & $5.06(1.43-17.84)$ & 0.012 & $4.41(1.21-16.05)$ & 을 \\
\hline
\end{tabular}

For multivariable logistic regression analysis, odds ratio and $95 \%$ confidence interval are presented. Odds ratios are calculated for CRC late-stage presentation. Only significant results. are shown in the multivariate analysis. The reference category has an odds ratio of 1.00 .

emergency case such as obstruction or perforation, this may be the reason why low income is not presented as a risk factor.

Other variable related to the surgical emergency is having a more advanced clinical stage; this factor has already been identified in other series ${ }^{18,19}$; even more, these tumors have also been associated with a more aggressive pathology. CRC diagnosed in late-stage has an OR of 1.28-4.8 $(p<0.05)$ for emergency presentation, as compared with earlier stages ${ }^{9}$. With the aforementioned, we can say that people either present as an emergency because it is the first symptom of a more aggressive tumor or because of the late access to medical facilities even though they had been symptomatic for a long time. Other factors, such as age ${ }^{20,21}$, marital status, and sex ${ }^{16,20,21}$, were not risk factors for emergent presentation in our study, as seen by other authors.

The limitations of our study are largely attributable to the retrospective design. The single institutional nature of our investigation is prone to selection bias. As previously mentioned, our institution is not a firstcontact hospital, and this represents an important limitation to our study, especially when interpreting the low rate of emergency surgery. The sample size could represent a risk of bias for a multivariate analysis, which could lead to underestimation of the independent variables. Despite these limitations, we consider that our results could lead to improvements in CRC screening and to identify patients at risk, especially patients who live in rural areas, with low-income status, or patients with a family history of cancer.

\section{Conclusions}

A $7.7 \%$ rate of emergency CRC surgery was found in our study. Although some patient-related factors, such as the family history of cancer, income status, place of residence, and TNM clinical stage, demonstrated a significant difference in the univariate analysis, only income status and clinical stage remained as independent predictors in the multivariate analysis. We also found an alarmingly low rate of CRC diagnosed by screening colonoscopy. Based on these data, policies and interventions for optimizing screening and preventing emergency presentations should be proposed to improve patients outcomes.

\section{Acknowledgments}

We would like to thank José Eeazim for helping us in collecting data.

\section{Conflicts of interest}

The authors declare that they have no conflicts of interest.

\section{Funding}

There were no grants/funds used for this research project. 


\section{Ethical disclosures}

Protection of human and animal subjects. The authors declare that no experiments were performed on humans or animals for this study.

Confidentiality of data. The authors declare that they have followed the protocols of their work center on the publication of patient data.

Right to privacy and informed consent. The authors declare that no patient data appear in this article.

\section{References}

1. Bray F, Ferlay J, Soerjomataram I, Siegel RL, Torre LA, Jemal A. Global cancer statistics 2018: GLOBOCAN estimates of incidence and mortality worldwide for 36 cancers in 185 countries. CA Cancer J Clin. 2018:68:394-424.

2. McArdle CS, Hole DJ. Emergency presentation of colorectal cancer is associated with poor 5-year survival. Br J Surg. 2004;91:605-9.

3. McPhail S, Elliss-Brookes L, Shelton J, Ives A, Greenslade M, Vernon S, et al. Emergency presentation of cancer and short-term mortality. $\mathrm{Br} \mathrm{J}$ Cancer. 2013;109:2027-34.

4. Chiarugi M, Galatioto C, Panicucci S, Scassa F, Zocco G, Seccia M Oncologic colon cancer resection in emergency: are we doing enough? Surg Oncol. 2007;16:S73-7.

5. Shah NA, Halverson J, Madhavan S. Burden of emergency and non-emergency colorectal cancer surgeries in West Virginia and the USA. J Gastrointest Cancer. 2013:44:46-53.

6. Sjo OH, Larsen S, Lunde OC, Nesbakken A. Short term outcome after emergency and elective surgery for colon cancer. Colorectal Dis. 2009;11:733-9.

7. Abdelrazeq AS, Scott N, Thorn C, Verbeke CS, Ambrose NS, Botterill ID, et al. The impact of spontaneous tumour perforation on outcome following colon cancer surgery. Colorectal Dis. 2008;10:775-80.
8. Jiang JK, Lan YT, Lin TC, Chen WS, Yang SH, Wang HS, et al Primary vs. delayed resection for obstructive left-sided colorectal cancer: impact of surgery on patient outcome. Dis Colon Rectum. 2008;51:306-1N

9. Zhou Y, Abel GA, Hamilton W, Pritchard-Jones K, Gross CP, Walten FM, et al. Diagnosis of cancer as an emergency: a critical review of current evidence. Nat Rev Clin Oncol. 2017;14:45-56.

10. Morris EJ, Taylor EF, Thomas JD, Quirke P, Finan PJ, Colemañ MP, et al. Thirty-day postoperative mortality after colorectal cancer surgery in England. Gut. 2011;60:806-13.

11. Wong SK, Jalaludin BB, Morgan MJ, Berthelsen AS, Morgan A, Gatenby $\mathrm{AH}$, et al. Tumor pathology and long-term survival in emergency colorectal cancer. Dis Colon Rectum. 2008:51:223-30.

12. Comber $H$, Sharp $L$, de Camargo Cancela $M$, Haase $T$, Johnson $H$, Pratschke J. Causes and outcomes of emergency presentation of Pectal cancer. Int J Cancer. 2016;139:1031-9.

13. Askari A, Nachiappan S, Currie A, Bottle A, Abercrombie J, Athanasiou T, et al. Who requires emergency surgery for colorectal cancer and can national screening programs reduce this need? Int J Surg. 2017:42:60-8.

14. Brannstrom F, Gunnarsson U. Risk factors for local recurrence after emergency resection for colon cancer: scenario in Sweden. Dig Surg. 2016;33:503-8.

15. Schlottmann F, Strassle PD, Cairns AL, Herbella FA, Fichera A, Patti MG Disparities in Emergent Colectomy for Colorectal Cancer Contribute to Inequalities in Postoperative Morbidity and Mortality in The US Health Care System. Scand J Surg. 2019;109:102-7.

16. Gunnarsson H, Ekholm A, Olsson LI. Emergency presentation and socioeconomic status in colon cancer. Eur J Surg Oncol. 2013;39:831-6.

17. Smith JJ, Tilney HS, Heriot AG, Darzi AW, Forbes H, Thompson MR, et al. Social deprivation and outcomes in colorectal cancer. $\mathrm{Br}$ JSurg. 2006;93:1123-31.

18. Ghazi S, Berg E, Lindblom A, Lindforss U, Low-Risk Colorectal Cancer Study Group. Clinicopathological analysis of colorectal cancer: a comparison between emergency and elective surgical cases. World J Jurg Oncol. 2013;11:133.

19. Papadimitriou GM, Georgiades CP, Vougas V, Vardas K, Drakopoutos S. Emergency surgery for obstructing colorectal malignancy: prognostic and risk factors. J BUON. 2015;20:406-12.

20. Askari A, Malietzis G, Nachiappan S, Antoniou A, Jenkins J, Kennēedy R, et al. Defining characteristics of patients with colorectal cancer requtiring emergency surgery. Int J Colorectal Dis. 2015;30:1329-36.

21. Moolla Z, Madiba TE. Trends in demographics and management of obstructing colorectal cancer. World J Surg. 2014;38:2466-70. 